\title{
Porcupine Abyssal Plain Sustained Observatory Monitors the Atmosphere to the Seafloor on Multidecadal Timescales
}

\author{
By Andrew R. Gates, Susan E. Hartman, Jon Campbell, Christopher Cardwell, Jennifer M. Durden, \\ Anita Flohr, Tammy Horton, Steven Lankester, Richard S. Lampitt, Charlotte Miskin-Hymas, Corinne Pebody, \\ Nick Rundle, Amanda Serpell-Stevens, and Brian J. Bett
}

Through international collaborations and advances in technology, ocean observatories are increasingly capable of monitoring over long time periods. The Porcupine Abyssal Plain Sustained Observatory (PAP-SO), located at $4,850 \mathrm{~m}$ depth in the Northeast Atlantic, is one of a small number of oceanic sites that has achieved monitoring to full ocean depths over several decades. It has monitored seafloor ecology since 1985, water column particle flux since 1992, and surface ocean and atmosphere parameters since 2003. The observatory is serviced annually, providing the opportunity to carry out conventional shipbased observations, sensor comparison, and sampling.

From the start, PAP-SO has sought to understand longterm change in the ocean-from surface to seafloor. The initial aim was to study seasonality in the supply of food particles that settle from the surface ocean to the deepsea floor and their role in structuring the ecosystem. Today, observatory research is increasingly focused on the causes and consequences of multidecadal change and on monitoring essential ocean variables such as ocean temperature and salinity; carbon dioxide, oxygen, and nutrient content; particulate matter; and phytoplankton, zooplankton, and seafloor invertebrate abundance (Figure 1).

The observatory also provides an excellent testbed for new sensors and platforms. Increasing use of autonomous systems has expanded the spatial extent and temporal resolution of observations. Autonomous vehicles host high-definition deep-sea cameras that capture photos of animals, and sensors mounted on underwater gliders collect oceanographic measurements to track the development of the spring phytoplankton bloom.

Observations of multidecadal duration are essential for the detection of long-term change in the ocean and are key to understanding our varying climate. The latest PAP-SO results demonstrate the importance of long-term records of ocean variables and processes (e.g., Hartman et al., 2021). For example, observatory data have revealed increased seasonal variability in seawater $\mathrm{CO}_{2}$ and a decline in $\mathrm{pH}$, driven by biological productivity. Close to the abyssal seafloor ( $>3,000 \mathrm{~m}$ depth), sampling of scavenging crustacean populations since 1985 has shown a major change in the dominant species that may be linked to upper ocean climate as assessed by the Atlantic Multidecadal Oscillation-a 60-80-year cycle in sea surface temperature.

The scientific results, underlying data, and biological specimen collections from PAP-SO are made publicly available and are used to support international ocean observing initiatives. The UK National Oceanography Centre operates the observatory collaboratively with the UK Met Office, and is primarily supported by the UK Natural Environment Research Council's Climate Linked Atlantic Sector Science project.

\section{REFERENCE}

Hartman, S.E., B.J. Bett, J.M. Durden, S.A. Henson, M. Iveren, R.M. Jeffreys, T. Horton, R. Lampitt, and A.R. Gates. 2021. Enduring science: Three decades of observing the Northeast Atlantic from the Porcupine Abyssal Plain Sustained Observatory (PAP-SO). Progress in Oceanography 191:201508, https://doi.org/10.1016/ j.pocean.2020.102508.

\section{DATA}

https://www.bodc.ac.uk/data/bodc_database/nodb/data_collection/5912/

\section{BIOLOGICAL SPECIMENS}

https://noc.ac.uk/facilities/discovery-collections

ARTICLE DOI: https://doi.org/10.5670/oceanog.2021.supplement.02-12
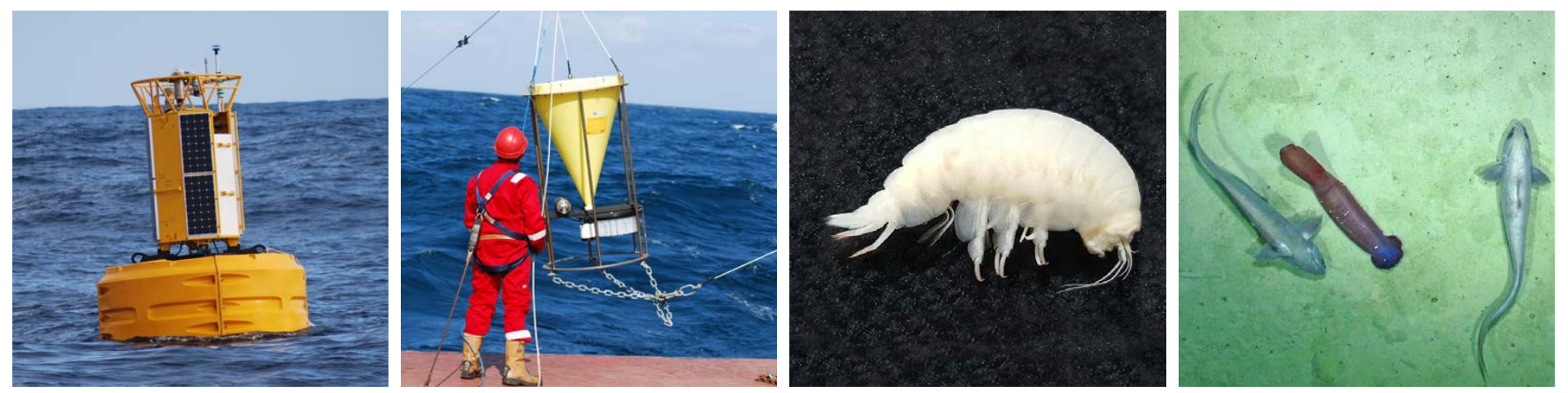

FIGURE 1. The Porcupine Abyssal Plain Sustained Observatory monitors essential ocean variables from the atmosphere to the seafloor $(4,850 \mathrm{~m})$, with a satellite-linked surface buoy, sediment traps deep in the water column $(3,000 \mathrm{~m})$, the collection of specimens including scavenging crustaceans near the seafloor, and photographic surveys of wildlife nearly $5 \mathrm{~km}$ beneath the sea surface. 


\section{AUTHORS}

Andrew R. Gates (arg3@noc.ac.uk) and Susan E. Hartman, National Oceanography Centre, Southampton, UK. Jon Campbell, Campbell Ocean Data, UK. Christopher Cardwell, Jennifer M. Durden, Anita Flohr, and Tammy Horton, National Oceanography Centre, Southampton, UK. Steven Lankester, Met Office, UK. Richard S. Lampitt, National Oceanography Centre, Southampton, UK. Charlotte Miskin-Hymas, British Oceanographic Data Centre, National Oceanography Centre, Southampton, UK. Corinne Pebody, Nick Rundle, Amanda Serpell-Stevens, and Brian J. Bett, National Oceanography Centre, Southampton, UK.

\section{ARTICLE CITATION}

Gates, A.R., S.E. Hartman, J. Campbell, C. Cardwell, J.M. Durden, A. Flohr, T. Horton, S. Lankester, R.S. Lampitt, C. Miskin-Hymas, C. Pebody, N. Rundle, A. Serpell-Stevens, and B.J. Bett. 2021. Porcupine Abyssal Plain Sustained Observatory monitors the atmosphere to the seafloor on multidecadal timescales. P. 29 in Frontiers in Ocean Observing: Documenting Ecosystems, Understanding Environmental Changes, Forecasting Hazards. E.S. Kappel, S.K. Juniper, S. Seeyave, E. Smith, and M. Visbeck, eds, A Supplement to Oceanography 34(4), https://doi.org/ 10.5670/oceanog.2021. supplement.02-12.

\section{COPYRIGHT \& USAGE}

This is an open access article made available under the terms of the Creative Commons Attribution 4.0 International License (https://creativecommons.org/ licenses/by/4.0/), which permits use, sharing, adaptation, distribution, and reproduction in any medium or format as long as users cite the materials appropriately, provide a link to the Creative Commons license, and indicate the changes that were made to the original content. 